\title{
Marx e o capitalismo do século XXI
}

\author{
Marx and the 21st century capitalism
}

\author{
ROSA MARIA MARQUES **** \\ PATRICK RODRIGUES ANDRADE ${ }^{+,++}$
}

\begin{abstract}
RESUMO: Este artigo tem como objetivo analisar o capitalismo contemporâneo à luz da contribuição de Marx em O Capital. Para isso, na primeira parte são discutidos sua compreensão sobre o capital monetário, o capital portador de juros e o capital fictício, enfatizando os aspectos fetichizados e a autonomização que esses últimos conquistaram com relação à produção de mercadorias, isto é, de novo valor. $\mathrm{Na}$ segunda parte são analisados o volume assumido pelo capital fictício no capitalismo mundial e suas consequências para o interior das empresas e para a manutenção do emprego, entre outras. Entre suas conclusões aponta-se que essa relativa autonomização não constitui uma anomalia ou cancro. Ao contrário, é expressão do desenvolvimento lógico da forma capital, quando a ele não se colocam freios, dada a situação de recuo em que se encontram os trabalhadores no plano internacional.

PALAVRAS-CHAVE: Capital portador de juros; capital fictício; capitalismo contemporâneo.
\end{abstract}

ABSTRACT: This article aims to analyze contemporary capitalism in the light of Marx's contribution in The Capital. For this, in the first part their understanding of money capital, interest-bearing capital and fictitious capital are discussed, emphasizing the fetishized aspects and the autonomy that the latter achieved in relation to the production of goods, that is, new value. In the second part, the volume assumed by fictitious capital in world capitalism and its consequences for the interior of companies and for the maintenance of employment, among others, are analyzed. Among its conclusions, it is pointed out that this relative autonomy does not constitute an anomaly or cancer. On the contrary, it is an expression of the logical development of the capital form, when there are no restraints on it, given the situation of retreat in which workers are at the international level.

KEYWORDS: Interest-bearing capital; fictitious capital; contemporary capitalism.

JEL Classification: E11; F3O; G10.

\footnotetext{
* Professora titular do Departamento de Economia e do Programa de Estudos Pós-Graduados em Economia Política da Pontifícia Universidade Católica de São Paulo (PUCSP), São Paulo/SP, Brasil. E-mail: rosamkmarques@gmail.com. Orcid: https://orcid.org/0000-0002-5624-0885.

* Líder do Grupo de Pesquisa Políticas para o Desenvolvimento Humano (PDH).

+ Professor do Departamento de Economia da PUCSP, São Paulo/SP, Brasil. E-mail: pkandrade@gmail. com. Orcid: https://orcid.org/0000-0001-7651-5439.

++ Pesquisador do PDH. Submetido: 23/Maio/2019; Aprovado: 2/Abril/2020.
} 
Passados 150 anos da publicação do Livro I de O Capital, o que Marx ainda nos tem a dizer? De que forma sua compreensão sobre as bases do funcionamento do capitalismo, bem como de suas leis e contradições, pode nos ajudar a compreender os traços maiores da contemporaneidade, particularmente com relação ao alto nível de financeirização atingido no século XXI? A presença dominante do capital portador de juros (com destaque para o capital fictício), definindo as relações econômicas e sociais no plano nacional e mundial, é meramente fruto das circunstâncias ou é expressão de sua forma mais acabada ou desenvolvida, que foi sempre idealmente perseguida pelo capital? A existência de um volume impressionante e exacerbado de capital fictício não revela a necessidade premente da superação do capitalismo, posto que ele não guarda nenhuma relação com a criação do valor e, portanto, não participa da geração de emprego e renda da imensa maioria dos trabalhadores assalariados?

É na busca das respostas a essas perguntas que nos debruçamos sobre a leitura de O Capital. Nosso intuito é evidenciar, principalmente para as gerações mais novas, de que forma as categorias analisadas por Marx nos permitem desvendar o capitalismo contemporâneo. Para isso, dividimos a exposição deste texto em três grandes partes. Na primeira, tratamos de resgatar o tratamento que Marx concede ao capital monetário, o capital portador de juros e ao capital fictício. Suas principais conclusões são chave para o entendimento da parte seguinte do texto, que trata do capital fictício na atualidade. É à luz dessas conclusões que podemos entender de que forma o capital fictício está capturando os demais capitais, impondo sua lógica de curto prazo, tornando as empresas um mero apêndice dele e revelando o caráter retrógrado do capitalismo, que não mais constitui meio de melhora das condições de reprodução da vida humana.

\section{DO CAPITAL MONETÁRIO AO CAPITAL PORTADOR DE JUROS E AO CAPITAL FICTÍCIO}

\section{A ficção produzida pelo movimento real do capital}

No segundo parágrafo do capítulo 21 do Livro III, que trata do capital portador de juros, Marx afirma:

Dinheiro - considerado aqui como expressão autônoma de uma soma de valor, exista ela de fato em dinheiro ou em mercadorias - pode na base da produção capitalista ser transformado em capital e, em virtude dessa transformação, passar de um valor dado para um valor que se valoriza a si mesmo, que se multiplica. Produz lucro, isto é, capacita o capitalista a extrair dos trabalhadores determinado quantum de trabalho não-pago, mais-produto e mais-valia, e apropriar-se dele. Assim adquire, além do valor de uso que possui como dinheiro, um valor de uso adicional, a saber, o de funcionar como capital. Seu valor de uso consiste aqui jus- 
tamente no lucro que, uma vez transformado em capital, produz. Nessa qualidade de capital possível, de meio para a produção de lucro, torna-se mercadoria, mas uma mercadoria sui generis. Ou, o que dá no mesmo, o capital enquanto capital se torna mercadoria. (Marx, 1986a, p. 255)

À primeira vista, a sequência desse argumento pode sugerir apenas uma questão possivelmente relevante: o fato de o dinheiro ter também um valor de uso sui generis, aquele de produzir mais valor. Contudo, mesmo essa afirmação não carregaria em si nenhuma novidade; afinal, desde o capítulo 4 do Livro I Marx afirma ser o capital o valor em processo, valor que se valoriza. Ora, como dinheiro "nada mais é" do que a representação fenomênica do valor, isso seria apenas a ratificação de um argumento recorrente em O Capital. Mas a questão mais importante nesse parágrafo é a que segue: "Nessa qualidade de capital possível, de meio para a produção de lucro, torna-se mercadoria, mas uma mercadoria sui generis. Ou, o que dá no mesmo, o capital enquanto capital se torna mercadoria" (Marx, 1986a, p. 255 , itálico do autor, sublinhado nosso). Essas duas considerações, isto é, de capital possível e de capital enquanto mercadoria, apresentam níveis e implicações diferentes: a existência desse valor de uso específico do dinheiro confere a ele a capacidade de se tornar, por um lado, mercadoria e, por outro, capital em potencial.

A originalidade teórica de Marx não está em reconhecer que o dinheiro é (seja) uma mercadoria sui generis no modo de produção capitalista, ou mesmo que, sob a forma dinheiro, o valor socialmente estabelecido possa se converter em capital. Qualquer cabeça pensante que exista sob o modo de produção capitalista é capaz de formular tais considerações, e sem a necessidade de um arrazoado de centenas de páginas para tanto - aliás, até a chamada economia vulgar foi capaz de alçar voos teóricos semelhantes. O que denota a originalidade de Marx é dizer que a conversão em mercadoria e ser capital possível são propriedades inerentes ao capital portador de juros e que em nenhum momento do ciclo global de reprodução do capital essas propriedades se perdem ou são subsumidas. Reconhecer a permanência de tais propriedades permite a Marx operar uma diferenciação crucial para o "movimento real" da acumulação capitalista: distinguir o capital portador de juros do simples dinheiro, do capital monetário ou mesmo do chamado capital financeiro (tal qual este é usualmente tratado nas análises econômicas convencionais).

Nesta seção se explora a diferença entre dinheiro e capital-dinheiro e entre capital-mercadoria e mercadoria-capital. Para isso, é fundamental resgatarmos algumas conclusões anteriormente alcançadas por Marx.

A primeira delas diz respeito à diferença entre uma "economia de mercado" e uma "economia capitalista". Na organização ideal chamada "economia de mercado", todos os agentes são proprietários de algum "ativo" e os transacionam num locus chamado mercado. Neste tipo de organização o dinheiro tem como funções aquelas tradicionalmente abordadas pela ciência econômica: ser unidade de conta/medida (dos valores - objetivos ou subjetivamente formados), ser meio de troca entre os "agentes" e ser reserva de valor. O que acabamos de ilustrar pode ser representado pela seguinte fórmula geral: $\mathrm{M}-\mathrm{D}-\mathrm{M}$, em que $\mathrm{M}$ é mercadoria e $\mathrm{D}$ é dinheiro. 
Como é sabido, essa não é a fórmula geral do capital ou da produção capitalista, mas sim de uma simples circulação de mercadorias. Mas ela expressa uma questão relevante para nossa discussão: é possível explicarmos as funções do dinheiro sem nos referir à acumulação de capital ou mesmo à existência de capital (em contraposição ao trabalho). Todavia, mesmo considerando a acumulação de capital e a fórmula geral D - M - D' (em que D' é dinheiro acrescido), é também possível tecer considerações sobre o capital monetário (ou o financeiro) sem esse ter o mesmo estatuto teórico do conceito de capital portador de juros. Essa leitura de Marx carrega um problema central para a análise do estatuto teórico do capital portador de juros (e o fictício) em O Capital, que é o do papel do dinheiro na reprodução do capital.

De maneira simplificada, podemos dizer que todo o problema gira em torno do fato de que utilizar o dinheiro "como dinheiro" e utilizá-lo como "capital" são duas possibilidades abertas pelo "movimento real" (da prática capitalista), mas que devem ser conceituadas e analisadas de modo diferente.

A exposição crítica dos conceitos legados pela economia política clássica (valor, trabalho, capital, lucro, etc.) e a crítica dessa mesma economia política, em $\mathrm{O} C a$ pital, implica compreender que o capital não é simplesmente uma sucessão de categorias (dinheiro, mercadoria, mais-dinheiro; ou moeda, produção, circulação e apropriação), mas se constitui como referência a si mesmo, o que será explorado mais adiante. Referência essa que alcança o seu ápice justamente sob a forma do capital portador de juros.

Seu primeiro indício se expressa no momento em que desdobramos a própria fórmula geral do capital: D - D - M - D' - D'.

Como afirma Marx:

O que aparece aqui duplicado é 1) o dispêndio do dinheiro como capital e 2) seu refluxo como capital realizado, como $D^{\prime}$ ou $\mathrm{D}+\Delta \mathrm{D}$.

No movimento do capital comercial D - M - D', a mesma mercadoria muda 2 vezes ou - se um comerciante vende a outro - mais vezes de mãos; mas cada uma dessas mudanças de lugar da mesma mercadoria indica uma metamorfose, compra ou venda da mercadoria, por mais vezes que esse processo possa se repetir até sua queda definitiva no consumo.

Em M - D - M, por outro lado, ocorre dupla mudança de lugar do mesmo dinheiro, mas indica a metamorfose completa da mercadoria, que primeiro se transforma em dinheiro e, em seguida, de dinheiro em outra mercadoria.

No caso do capital portador de juros, ao contrário, a primeira mudança de lugar de D de modo algum constitui um momento, seja da metamorfose de mercadorias, seja da reprodução do capital. Isso ele só se torna no segundo dispêndio, nas mãos do capitalista funcionante, que com ele comercia ou o transforma em capital produtivo. A primeira mudança de lugar de D expressa, aqui, apenas sua transferência ou remessa de A a B; 
uma transferência que costuma realizar-se sob certas formas e garantias jurídica (MARX, 1986a, p. 257, grifos nossos)

Essa transferência monetária, de um capitalista A para um B, não constitui uma metamorfose do ciclo de reprodução do capital, ao contrário do "ciclo do capital monetário", apresentado por Marx no Livro II. No capítulo 1 do Livro II, a exposição das metamorfoses do ciclo é apresentada inicialmente como transformação da forma-dinheiro em capital monetário; um mesmo objeto, mas que passa a sustentar uma nova relação: passa a ser o suporte do valor de capital, uma propriedade que não deriva de o fato do capital monetário ser capital, mas sim dele ser dinheiro"

Agora, com o capital portador de juros, a análise se mostra muito mais complexa. É o capital que se torna mercadoria, e se faz capital possível.

O segredo deste processo está no fato de que, para o escândalo de especialistas em monetary theory, o capital portador de juros existe como capital independentemente de seu movimento real (ingresso de uma soma de dinheiro no processo de produção e realização de mais-valia).

[...] O possuidor de dinheiro que quer valorizar seu dinheiro como capital portador de juros aliena-o a um terceiro, lança-o na circulação, torna-o mercadoria como capital; não só como capital para si mesmo, mas também para outros; não é meramente capital para aquele que o aliena, mas é entregue ao terceiro de antemão como capital, como valor que possui o valor de uso de criar mais-valia, lucro; como valor que se conserva no movimento e, depois de ter funcionado, retorna para quem originalmente o despendeu, nesse caso o possuidor de dinheiro; portanto afasta-se dele apenas por um período, passa da posse de seu proprietário apenas temporariamente à posse do capitalista funcionante, não é dado em pagamento nem vendido, mas apenas emprestado; só é alienado sob a condição, primeiro, de voltar, após determinado prazo, a seu ponto de partida, e, segundo, de voltar como capital realizado, tendo realizado seu valor de uso de produzir mais-valia. (Marx, 1986a, p. 259, grifos nossos)

\footnotetext{
${ }^{1}$ Isso porque o capital monetário, tal como desenvolvido no Livro II, cumpre, na verdade, as funções próprias do dinheiro (meio universal de compra e meio universal de pagamento). A função de capital do capital monetário se dá pelo seu papel no ciclo de reprodução, i.e.,, pelo seu vínculo com o capital produtivo. O próprio Marx resgata esse ponto no capítulo 21 do Livro III: "na medida em que estão funcionando realmente, desempenhando realmente seu papel no processo, o capital-mercadoria atua aqui apenas como mercadoria e o capital monetário apenas como dinheiro. Em nenhum momento isolado da metamorfose, considerado por si, o capitalista vende a mercadoria como capital ao comprador, embora para ele esta represente capital, ou aliena o dinheiro como capital ao vendedor. Em ambos os casos, ele aliena a mercadoria simplesmente como mercadoria e o dinheiro simplesmente como dinheiro, como meio de compra de mercadorias" (Marx, 1986a, p. 258).
} 
Há, nessa passagem do capítulo 21 (Livro III), dois aspectos importantes: i) há uma duplicação em potencial do capital, já que a mercadoria-capital assim o é para o prestamista e para o tomador do empréstimo; ii) uma das condições é que o capital realizado retorne acrescido de mais-valia.

Sobre o primeiro aspecto, Marx critica a posição de Proudhon precisamente porque, com o capital portador de juros, não há mudança de propriedade ou troca de equivalentes; ou seja, não se trata de uma relação de troca convencional (a qual sempre implica, para o comprador, ter a propriedade do objeto que foi comprado), não há entrega de valor - o capitalista que desempenha o papel de prestamista mantém o valor do que empresta. Se esse aspecto da duplicação do capital, sem que haja transferência de propriedade ou cessão de valor, é razoavelmente compreendido, o mesmo não se pode afirmar sobre o segundo aspecto - o de que o capital necessitaria retornar acrescido de mais valor.

Que é então que continua enigmático para ele [Proudhon, tratado aqui como caso ilustrativo do argumento de Marx] no movimento peculiar do capital portador de juros? As categorias: comprar, preço, entregar objetos, e a forma direta em que aparece aqui a mais-valia; em suma, o fenômeno de que aqui o capital enquanto capital se tornou mercadoria, que, portanto, a venda se transformou em empréstimo, o preço em participação no lucro.

O retorno do capital a seu ponto de partida é, em geral, o movimento característico do capital em seu ciclo global. Isso não é característico apenas do capital portador de juros. O que o distingue é a forma externa, dissociada do ciclo mediador. (Marx, 1986a, p. 261)

Esse segundo aspecto é justamente uma faceta do caráter enigmático sugerido por Marx: o que ocorre pela dissociação, operada pela lógica do capital portador de juros, do ciclo mediador de reprodução global do capital (onde antes se identificava D - M - D', pode ser sintetizado simplesmente como D - D').

De onde provém essa capacidade do capital portador de juros de se apresentar como externo ao movimento do capital em geral? Analogamente à explicação dada para o fetichismo da mercadoria, essa capacidade provém de sua própria forma; ela pressupõe que o dinheiro, operando como capital portador de juros, é efetivamente empregado como capital (enquanto função, isto é, que ele inicie o ciclo do capital monetário - como apresentado no capítulo 1 do Livro II - e produza mais-valia).

É, aliás, justamente esse o valor de uso do dinheiro como capital, “a capacidade de produzir o lucro médio" (Marx, 1986a, p. 264), lucro do qual uma cota parte é o juro, isto é, o juro é uma dedução do lucro. Se o dinheiro enquanto capital possível é uma mercadoria, e a capacidade de produzir lucro médio outorga a ele o direito a juros, não seria o juro o preço do dinheiro (ou, precisamente, do capital)? Marx argumenta que, a despeito da compreensão oferecida pela "economia vulgar", a ideia de juro como preço é completamente irracional. Como é 
possível que uma soma de valor (dinheiro) tenha um preço além do seu próprio preço (expresso enquanto montante de dinheiro)? Considerar o juro como um preço do dinheiro, mas que é qualitativamente distinto do que essa soma de dinheiro representa, "é uma contradição absurda" (Marx, 1986a, p. 266).

O juro é, na verdade, rendimento da aplicação do título e meio para a apropriação de trabalho alheio; a cessão do direito do capital, enquanto mercadoria, de comandar trabalho alheio (Marx, 1986a, p. 267). Uma conclusão importante alcançada por Marx é de que não existe nenhuma lei econômica que determine a taxa de juros em um país, o que torna um contrassenso se falar em uma taxa natural de juros. O único limite que se revela para a taxa de juro é a taxa média de lucro - como o juro é uma dedução do lucro, é impossível que a reprodução do capital possa ocorrer normalmente com um nível de juro superior à massa de lucro extraída.

A maneira como as duas pessoas que têm direito ao lucro o dividem entre si é em si e para si um fato puramente empírico, pertencente ao reino do acaso, do mesmo modo que a repartição das parcelas percentuais do lucro comum de uma empresa societária entre os diversos sócios. $\mathrm{Na}$ repartição entre mais-valia e salário, na qual se baseia essencialmente a determinação da taxa de lucro, atuam de modo determinante dois elementos inteiramente diversos, força de trabalho e capital; são funções de duas variáveis independentes que se fixam mutuamente limites; e de sua diferença qualitativa surge a repartição quantitativa do valor produzido [...]. No caso do juro, não acontece nada desse gênero. Aí, a distinção qualitativa surge, como logo veremos, ao contrário, da repartição puramente quantitativa da mesma soma de mais-valia. (Marx, 1986a, p. 273, grifos do autor)

A distinção qualitativa, a qual se refere Marx, é evidenciada pela oposição, no interior do processo de reprodução do capital, entre o "capitalista monetário" (o proprietário da mercadoria-capital, o capital portador de juros) e o "capitalista funcionante" (o não -proprietário do capital, mas que atua no processo como capitalista ativo, seja na indústria ou no comércio). A questão concreta que se impõe é que o juro pago pelo capitalista ativo (o tomador dos recursos monetários) ao capitalista monetário "aparece, portanto, como aquela parte do lucro bruto que cabe à propriedade do capital como tal" (Marx, 1986a, p. 280); enquanto a parte do lucro auferida efetivamente pelo capitalista ativo "aparece agora ganho empresarial oriundo exclusivamente das operações ou funções que ele efetua com o capital no processo de reprodução" (Marx, 1986a, p. 280). Como resultado, o "movimento real", tal como o processo de acumulação se manifesta para a mentalidade capitalista, reforça a percepção de que o juro é "mero fruto da propriedade do capital, do capital em si, abstraído o processo de reprodução do capital, [n]a medida que ele não 'trabalha', não funciona [enquanto capital processante da produção]" (Marx, 1986a, p. 280, colchetes nossos).

Novamente, a originalidade analítica de Marx não é a de afirmar que a 
percepção capitalista do processo de produção seja um "erro", mas sim explicar porque, apesar da crítica científica da economia política oferecer explicações distintas sobre a estrutura da reprodução, a aparência do processo é justamente aquela formada na cabeça dos capitalistas (e reforçada pela economia vulgar e suas aporias). Um aspecto importante da análise de Marx é que ela explica também por que, na superfície dos fenômenos, eles aparecem de uma forma invertida. Por exemplo:

A concepção do ganho empresarial como salário de superintendência do trabalho, que surge de sua antítese com o juro, encontra mais apoio no fato de que parte do lucro pode ser separada, e se separa realmente, como salário, ou antes, pelo contrário, de que parte do salário, na base do modo de produção capitalista, aparece como parte integrante do lucro. (Marx, 1986a, p. 286)

A consolidação do juro, qualitativamente oposto ao lucro, sua ossificação, se funda na própria práxis capitalista - ainda que a investigação científica crítica da economia política explique ser o juro uma cota parte da mais-valia criada no processo produtivo e realizada na circulação. Sobre essa distinção qualitativa entre lucro e juro há outra implicação analítica relevante: como o caráter mercadoria do capital se impõe fora do processo de produção, a antítese do capital não se realiza com o trabalho, mas com outro capital. Como "o juro é uma relação entre dois capitalistas e não entre capitalista e trabalhador", o "caráter antitético do capital encontra expressão autônoma" (Marx, 1986a, p. 285 passim, grifo nosso).

Essa expressão autônoma é desenvolvida por Marx no capítulo 24 do Livro III, que versa sobre a relação de capital plenamente fetichizada na forma do capital portador de juros. A síntese D - D', cujos componentes são qualitativamente idênticos - afinal, trata-se de dinheiro no início e no final do ciclo -, e para a qual a única diferença evidente é quantitativa - dispensando a mediação do processo de produção e de circulação -, permite, ao capital, aparecer como fonte autocriadora do juro. De maneira direta:

A coisa (dinheiro, mercadoria, valor) já é capital como mera coisa, e o capital aparece como simples coisa; o resultado do processo global de reprodução aparece como propriedade que cabe por si a uma coisa; depende do possuidor do dinheiro, isto é, da mercadoria em sua forma sempre intercambiável, se ele quer despendê-lo como dinheiro ou alugá-lo como capital. Na forma do capital portador de juros, portanto, esse fetiche automático está elaborado em sua pureza, valor que valoriza a si mesmo, dinheiro que gera dinheiro, e ele não traz nenhuma marca de seu nascimento. A relação social está consumada como relação de uma coisa, do dinheiro, consigo mesmo. (Marx, 1986a, pp. 293-294).

Aquele processo complexo, sintetizado pela fórmula D - M - D', que implica: i) um devir qualitativo, no qual o valor transita de uma forma a outra (dinheiro, meios de produção, força de trabalho, mercadoria e retorno à forma dinheiro); e 
ii) um devir quantitativo, no qual o valor, ao final do processo, ressurge acrescido de mais valor, num processo expansivo; pode se apresentar diante do mundo do capital como um devir meramente tautológico, dinheiro que gera automaticamente mais dinheiro, simplesmente uma coisa em relação consigo mesma.

Se, no capítulo 1 do Livro II, Marx já apontara D' como resultado final do “ciclo do capital monetário", D' aparece como produto do próprio capital monetário, em que desaparecem as diferenças qualitativas entre as mercadorias (meios de produção e força de trabalho) envolvidas na produção, restando apenas a diferença quantitativa (de um capital inicial acrescido de um rendimento), em que se tem apenas "a expressão sem conceito da relação de capital, sob cuja forma o capital realizado aparece em sua expressão monetária” (Marx, 2014, p. 127, grifos nossos). Sob a lógica do capital portador de juros, na qual as relações capitalistas se encontram plenamente reificadas (fetichizadas), aquela expressão sem conceito do capital monetário encontra seu fundamento social: o próprio sistema de conexões a-conceituais da percepção capitalista - para a qual não concorre qualquer reflexão sobre o conteúdo das relações sociais.

A análise de Marx, incluindo considerações estabelecidas ainda nos primeiros capítulos do Livro I de O Capital, encontra a superfície evidente e aparente da realidade capitalista. Como afirma o próprio:

Dinheiro é justamente a forma em que a diferença entre as mercadorias como valores de uso está apagada [graças à forma geral do valor, apresentada no capítulo 1 do Livro I] e, por conseguinte, também as diferenças entre os capitais industriais que consistem nessas mercadorias e suas condições de produção [questão apontada no capítulo 1 do Livro II]; é a forma em que valor - e aqui capital - existe como valor de troca autônomo [consideração estabelecida já no capítulo 4 do Livro I]. No processo de reprodução do capital, a forma-dinheiro é evanescente, um mero momento de transição [conclusão do capítulo 1 do Livro II]. No mercado monetário, ao contrário, o capital existe sempre nessa forma [...]. Gerar dinheiro parece tão próprio ao capital nesta forma de capital monetário [portador de juros] quanto o crescer, às árvores. (Marx, 1986a, p. 294, acréscimos nossos nos colchetes)

Toda fundamentação sócio-histórica de desenvolvimento capitalista e as conexões conceituais relativas ao modo de produção são naturalizadas: entre o crescimento vegetativo de seres vivos e a expansão automática do valor não há diferença ordinária alguma.

Essa naturalização / reificação carrega consigo outro determinante: "a identidade da mais-valia com o mais-trabalho impõe um limite qualitativo à acumulação do capital: a jornada global de trabalho" (Marx, 1986a, p. 299). Sob a forma irracional do juro, o limite à acumulação é quantitativo, isto é, a jornada de trabalho não afeta o potencial de acumulação do capital. 
Sobre esse fetiche autômato perfeito que se realiza com a forma capital portador de juros conclui Marx:

No capital portador de juros está, no entanto, consumada a concepção do fetiche-capital, a concepção que atribui ao produto acumulado do trabalho, e ainda fixado na forma de dinheiro, o poder de produzir, em virtude de uma qualidade inata e secreta, como um puro autômato, em progressão geométrica, mais-valia, de modo que esse produto acumulado do trabalho, conforme pensa o Economist, já há muito tempo descontou toda a riqueza do mundo, para todo o sempre, como algo que lhe pertence e lhe cabe de direito. (Marx, 1986a, p. 299)

\section{O movimento real da ficção: do capital portador de juros ao capital fictício.}

O trecho do capítulo 24 do Livro III, que encerra nossa seção anterior, não deve ser lido fortuitamente. Pelo menos duas considerações trazem implicações conceituais cruciais: i) o valor de uso do capital portador de juros - que é justamente render juros - é reificado em uma forma sem conteúdo necessário; ii) o pertencimento, por direito, de toda a riqueza ao capital portador de juros. Mais do que um mero recurso estilístico, a relação riqueza futura e apropriação por direito são elementos-chave para a compreensão do conceito de capital fictício.

Como mencionado na introdução deste artigo, à medida que leitura da seção V do Livro III avança, especialmente a partir do capítulo 25 (Crédito e capital fictício), a organicidade do texto se torna cada vez mais precária, com longos trechos de citações diretas de materiais compilados no manuscrito original e comentários cada vez mais localizados e reduzidos sobre o conteúdo selecionado. Extrair novos conceitos produzidos por Marx e estabelecer as relações analíticas com os conceitos e relações apresentadas anteriormente se tornam um desafio muito maior. Não obstante, há alguns determinantes que permitem avanços importantes do corpo teórico desenvolvido em O Capital.

O desenvolvimento do sistema bancário e de crédito, ainda que não seja o objeto de análise central de Marx, aponta para um fenômeno de implicações significativas:

a) A concentração do capital monetário, anteriormente retalhado em pequenas somas, e agora unificado em grandes volumes, constitui um "poder monetário" (Marx, 1986a, p. 303);

b) O desenvolvimento de um sistema de crédito mais robusto propicia um ambiente mais favorável à obtenção de adiantamentos sobre rendimentos futuros (mercadorias ainda não vendidas, juros provenientes de outros produtos financeiros, lucro esperado etc.). Tal possibilidade é um estímulo à própria sobreprodução/sobreacumulação, 
cujo objetivo imediato pode ser justamente conseguir adiantamentos de crédito sobre a produção e os rendimentos futuros;

c) Com a transformação do "capitalista ativo" em "administrador", sua função social é reduzida a de dirigente de capital alheio; os proprietários desse capital são, por sua vez, reduzidos a capitalistas monetários (cujo rendimento se dá sob a forma de juros e não de lucro propriamente);

d) Como na sociedade por ações, a função de dirigente capitalista é separada da propriedade do capital, as funções vinculadas à propriedade do capital são transformadas em funções sociais - passíveis de execução por não proprietários de capital.

Tais aspectos estão entre os principais determinantes explicativos da capacidade de dominância econômica (e de exercício de dominação política) do capital portador de juros. Os fundamentos e características do próprio capital portador de juros tendem à constituição daquilo que é chamado (já em O Capital) de "nova aristocracia financeira"; a potencialidade de dispor sobre o "capital social, não próprio, dá-lhe disposição sobre trabalho social"; o potencial de expropriação, que constitui o ponto de partida do modo de produção capitalista, "estende-se aqui dos produtores diretos até os próprios capitalistas pequenos e médios" (Marx, 1986a, pp. 333-334, passim). Assim, sob a égide do capital portador de juros, a própria dinâmica de expropriação capitalista alcança seu ápice, expandindo-se para todos os "indivíduos" (inclusive capitalistas).

Como aponta Marx, a incapacidade de identificar esse fenômeno (o potencial do capital portador de juros dispor de todo o trabalho social) se deve à confusão entre money capital (capital monetário) e moneyed capital (capital portador de juros). O capital portador de juros não é simplesmente capital que financia o ciclo de reprodução do capital; isto é, para Marx, o capital portador de juros não pode ser confundido com a noção tradicional de capital financeiro, tal como ele se difundiu no pensamento econômico tradicional.

Sintetizando a exposição de Marx sobre o capital portador de juros, têm-se as seguintes determinações: i) ele dispõe de um valor de uso específico, que é o potencial de "produzir mais-valia"; ii) há uma oposição, posta por essa forma de capital, entre juro e lucro do empresário, como se tais rendimentos tivessem origens diferentes (de tal modo que ela se concretiza na oposição entre capitalista ativo e proprietário da mercadoria capital); iii) forma-se uma objetivação fetichista, que põe esse capital como um fenômeno naturalizado, formal, desligado de conteúdos sociais mais complexos. Desse modo, "a forma de capital portador de juros faz com que cada rendimento monetário determinado e regular apareça como juro de um capital, quer provenha de um capital ou não" (Marx, 1986b, p. 10). O capital portador de juros, enquanto fetiche perfeito, "matriz de todas as formas aloucadas", imprime a lógica da capitalização a toda existência capitalista. 
A lógica rentista, com sua "raciocinação ideológica", produz dois tipos de capital: o "capital ilusório" e o "capital fictício". Como afirma Marx:

A coisa é simples: suponhamos que a taxa média de juros seja de $5 \%$ ao ano. Uma soma de 500 libras esterlinas, se transformada em capital portador de juros, proporcionaria, portanto, anualmente 25 libras esterlinas. Considera-se, assim, toda receita fixa anual de 25 libras esterlinas como juro de um capital de 500 libras esterlinas. Isso, entretanto, é e permanece uma representação puramente ilusória, excetuado o caso em que a fonte das 25 libras esterlinas - seja esta um simples título de propriedade, respectivamente um crédito ou um elemento real de produção, como, por exemplo, uma propriedade fundiária - seja diretamente transferível ou assuma uma forma em que se torna transferível. (Marx, 1986b, p. 10, grifos nossos)

Um exemplo ilustrativo da diferença entre um capital ilusório e o capital fictício é a pretensa existência de alguma coisa como "capital humano". Essa noção expressa um dos pontos altos da concepção capitalista aloucada: ao invés de explicar a valorização do capital pela exploração econômica da força de trabalho, simples fato de a capacidade de trabalhar ser convertida em uma mercadoria transacionável da qual seu proprietário (o trabalhador) recebe um rendimento (o salário), funde a compreensão da própria força de trabalho com a do capital portador de juros.

Essa "mistificação", ou ilusão (objetiva, já que produzida pela estrutura das relações sociais de produção capitalista), é criticada por Marx através de dois argumentos práticos: $i$ ) o trabalhador precisa trabalhar para obter esse "juro" (seu salário), i.e.,, é necessário que haja precisamente o consumo da força de trabalho para que algum rendimento seja auferido, e; ii) o trabalhador é incapaz de monetizar todo o seu capital humano, i.e.,, ele não é capaz de converter todo o seu "estoque de força de trabalho" em dinheiro. Assim, como a força de trabalho não pode se converter completamente em um título transferível, elucubrações sobre "capital humano" revelam apenas uma expressão totalmente ilusória de capital.

A distinção entre as formas ilusórias de capital e o capital fictício reside na possibilidade de transferência da propriedade do rendimento. A lógica do capital portador de juros, levada ao paroxismo, se desdobra na forma de capital fictício, em que "toda a conexão com o processo real de valorização do capital se perde assim até o último vestígio, e a concepção do capital como autômato que se valoriza por si mesmo se consolida" (Marx, 1986b, p. 11). De tal sorte que, "como logo veremos, esse capital fictício tem seu próprio movimento" (Marx, 1986b, p. 10).

A dimensão fictícia desse capital se deve ao fato de que ele representa "apenas direitos acumulados, títulos jurídicos sobre produção futura, cujo valor monetário ou valor-capital ou não representa capital algum, [...] ou é regulado independentemente do valor do capital real que representam" (Marx, 1986b, p. 13). O aspecto fictício desse capital deriva do próprio entendimento que o capital portador de 
juros tem de si mesmo, ao se considerar capital com direito à rentabilidade, independentemente dos resultados alcançado pelo capital funcionante ${ }^{2}$.

Contudo, assim como no caso do fetichismo da mercadoria, o fenômeno não é fruto de uma abstração mental proveniente da cabeça pensante do cientista, nem, tampouco, um erro de análise do investigador - o capital fictício tem uma dimensão real bastante concreta. Sob a égide dos mercados financeiros, controlados por aquilo que Marx denominara de "aristocracia financeira" - que, por sua vez, dispõe de um "poder monetário" real -, o potencial de controle da reprodução desse grande negócio chamado Capital é mais real do que própria realidade ordinária costuma sugerir. Vale lembrar que corresponde ao capital fictício juros (lucros) também fictícios, posto que não são embasados na criação de mais valor apropriado pelo capitalista funcional, seja ele industrial ou comercial. Dessa maneira, a rentabilidade recebida pelos detentores de capital fictício não se constituiria punção sobre a mais-valia. No Brasil, essa leitura sobre os “juros" foi desenvolvida por Carcanholo e Nakatani (2007) e mencionada por Chesnais (2008).

$\mathrm{Na}$ contemporaneidade, ter essas conclusões presentes é essencial para compreendermos a verdadeira dimensão da atual dominância do capital portador de juros, especialmente com relação a seu capital fictício, que assume a forma de títulos, ações e derivativos.

\section{O CAPITAL FICTÍCIO NA ATUALIDADE}

Nos últimos anos, principalmente depois da crise da subprime, nos Estados Unidos, em 2007-2008, tornou-se lugar-comum entre os economistas dizer que o capitalismo contemporâneo apresenta elevado grau de financeirização e que o capital portador de juros se desenvolveu de forma desmesurada nas últimas décadas. Apesar disso, são poucos aqueles que se preocuparam em se debruçar para explicar as razões do ganho de proeminência desse capital sobre os demais a partir da própria lógica de reprodução do capital e para investigar as consequências disso em termos da dinâmica do capitalismo, do emprego e mesmo na reprodução da vida social. Pode-se dizer que essas indagações estão mais presentes no campo do pensamento marxista, embora haja importantes autores de outras escolas de pensamento que possam também ser lembrados, tal como Orléan (1999), Aglietta (2003) e Lordon (2003).

Nesta parte do texto temos dois objetivos: apresentar os dados que indicam o crescimento vertiginoso do capital portador de juros e do capital fictício, e as curvas econômicas mais relevantes, e chamar a atenção para o impacto da dominância

\footnotetext{
${ }^{2}$ A rigor, a rentabilidade, que é "inerente" ao capital portador de juros, tem como origem primeira o descolamento da forma preço em relação à forma valor (Andrade e Marques, 2017).
} 
do capital fictício sobre a gestão das empresas, o nível de emprego e renda. Para isso, nos apoiamos em autores que se destacaram na investigação desses aspectos, todos eles situados no campo marxista.

\section{O crescimento do capital fictício}

Segundo algumas estimativas, que não incluem os derivativos, em 2014 os ativos financeiros no mundo atingiram a incrível cifra de 294 trilhões de dólares; em 1990, eles eram apenas 19\% disso, somando 56 trilhões de dólares (Gráfico 1). O crescimento dos ativos foi extraordinário especialmente nos anos 1990, quando claramente sua expansão se acelerou (aumento de 111,8\% em 2000 com relação a 1990; de 91,7\% em 2010-2000; 42\% em 2014-2010). O valor dos ativos de 2014 equivale a mais de 5,7 vezes o de 1990 . No período, ainda, chama a atenção que os Empréstimos não securatizados, que representavam $43,1 \%$ do total de ativos em 1990, reduziram sua participação para 21,1\% em 2014 (embora, no período, tenham aumentado $181,8 \%$ ). Isso foi acompanhado pelo aumento relativo de todos os outros componentes.

Gráfico 1: Estoque global de ativos - US\$ trilhões

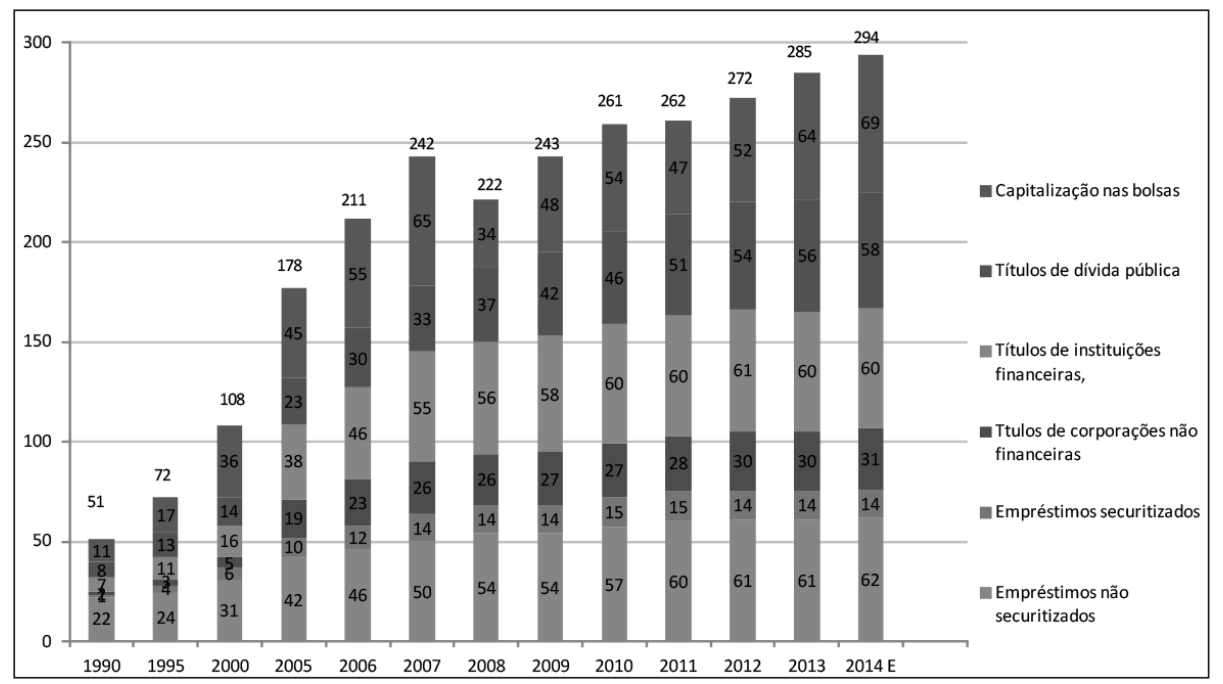

Fonte: McKinsey Global Institute, Haver, BIS, DB estimativas.

Também é interessante chamar a atenção para a evolução do valor de mercado das ações. Esse, após apresentar queda em 2008 (-48\%), voltou a crescer em todos os anos. A Tabela 1, de outra fonte, completa as informações do Gráfico 1 neste quesito. 
Tabela 1: Valor de mercado das empresas cotadas nas bolsas de valores (bilhões US\$)

\begin{tabular}{|l|c|c|c|c|c|c|c|c|c|c|c|c|}
\hline Discriminação & 2005 & 2006 & 2007 & 2008 & 2009 & 2010 & 2011 & 2012 & 2013 & 2014 & 2015 & 2016 \\
\hline $\begin{array}{l}\text { Área } \\
\text { do Euro }\end{array}$ & 6.209 & 8.568 & 10.062 & 4.990 & 6.671 & 6.439 & 5.400 & 6.134 & 7.708 & 7.001 & 6.121 & 6.218 \\
\hline $\begin{array}{l}\text { União } \\
\text { Europeia }\end{array}$ & 9.462 & 12.649 & 14.358 & 7.059 & 6.900 & 6.705 & 5.602 & 6.332 & 7.932 & 7.185 & $\mathrm{n} / \mathrm{d}$ & $\mathrm{n} / \mathrm{d}$ \\
\hline Mundo & 40.664 & 50.282 & 60.334 & 32.290 & 44.626 & 51.453 & 44.373 & 51.029 & 60.125 & 63.297 & 61.781 & 64.820 \\
\hline Alemanha & 1.202 & 1.638 & 2.105 & 1.111 & 1.292 & 1.430 & 1.185 & 1.486 & 1.936 & 1.739 & 1.716 & 1.716 \\
\hline Brasil & 475 & 710 & 1.370 & 592 & 1.337 & 1.546 & 1.229 & 1.227 & 1.020 & 844 & 491 & 759 \\
\hline Espanha & 960 & 1.323 & 1.800 & 948 & 1.435 & 1.172 & 1.031 & 995 & 1.117 & 993 & 787 & 705 \\
\hline $\begin{array}{l}\text { Estados } \\
\text { Unidos }\end{array}$ & 17.001 & 19.569 & 19.922 & 11.590 & 15.077 & 17.283 & 15.641 & 18.668 & 24.035 & 26.331 & 25.068 & 27.352 \\
\hline França & 1.759 & 2.428 & 2.740 & 1.472 & 1.946 & 1.912 & 1.554 & 1.808 & 2.301 & 2.086 & 2.088 & 2.157 \\
\hline Grécia & 145 & 201 & 265 & 90 & 113 & 68 & 34 & 45 & 83 & 55 & 42 & 37 \\
\hline Itália & 798 & 1.027 & 1.073 & 522 & 656 & 535 & 431 & 482 & 615 & 587 & $\mathrm{n} / \mathrm{d}$ & $\mathrm{n} / \mathrm{d}$ \\
\hline Portugal & 67 & 104 & 132 & 69 & 98 & 82 & 62 & 66 & 79 & 58 & 60 & 57 \\
\hline $\begin{array}{l}\text { Reino } \\
\text { Unido }\end{array}$ & 3.058 & 3.781 & 3.846 & 1.868 & $\mathrm{n} / \mathrm{d}$ & $\mathrm{n} / \mathrm{d}$ & $\mathrm{n} / \mathrm{d}$ & $\mathrm{n} / \mathrm{d}$ & $\mathrm{n} / \mathrm{d}$ & $\mathrm{n} / \mathrm{d}$ & $\mathrm{n} / \mathrm{d}$ & $\mathrm{n} / \mathrm{d}$ \\
\hline
\end{tabular}

Fonte: World Bank. http://data.worldbank.org/indicator/CM.MKT.LCAP.CD/countries?display=default

Se considerarmos os derivativos, o avanço do capital fictício, observado anteriormente, foi ainda mais espetacular (Tabela 2). Em apenas sete anos, de 2005 a 2012 , o saldo total dos derivativos aumentou $212,5 \%$, pouco recuando na crise provocada pela subprime.

Tabela 2: Saldos de Derivativos OTC (Valor nocional em trilhões US\$)

\begin{tabular}{|c|c|c|c|c|c|c|}
\hline & Câmbio & Taxa de juros & Commodities & CDS & Outros & Total \\
\hline 2005 & 31,364 & 211,97 & 5,434 & 13,908 & 34,994 & 297,67 \\
\hline 2006 & 40,271 & 291,582 & 7,115 & 28,65 & 47,228 & 414,846 \\
\hline 2007 & 56,238 & 393,138 & 8,455 & 57,894 & 79,616 & 595,341 \\
\hline 2008 & 49,753 & 418,678 & 4,427 & 41,868 & 77,237 & 591,963 \\
\hline 2009 & 49,181 & 449,875 & 2,944 & 32,693 & 69,207 & 603,9 \\
\hline 2010 & 57,796 & 465,26 & 2,922 & 29,898 & 45,17 & 601,046 \\
\hline 2011 & 63,349 & 504,117 & 3,091 & 28,626 & 48,592 & 647,775 \\
\hline 2012 & 67,358 & 489,703 & 2,587 & 25,069 & 47,851 & 632,568 \\
\hline
\end{tabular}

Fonte: BIS. Quarterly Review. Tabela 19. Vários números. Apud Marques e NakataNI (2014). 
Para os anos de 2013 a 2016, os dados dos derivativos apresentados pelo Bank for International Settlements (BIS) não são comparáveis à série da Tabela 2, provavelmente devido à mudança metodológica.

Se somarmos todos os componentes do capital fictício, verifica-se que foi contínuo seu distanciamento com relação à evolução da produção mundial. Isso revela o papel central que o capital portador de juros, principalmente na sua forma de capital fictício, tem assumido no capitalismo contemporâneo. Em 2012, o volume do capital fictício existente no mundo, compreendendo os títulos públicos, as ações e os derivativos, representava 10 vezes o PIB Mundial (MARQUES, 2015).

\section{O capital fictício e a crise do capitalismo}

A evolução, nos últimos 50 anos, de indicadores relevantes revela traços fundamentais do capitalismo contemporâneo. No Brasil é bastante conhecido o gráfico de Michel Husson (2010), no qual ele apresenta a evolução da taxa de lucro, da acumulação, do crescimento e da produtividade. Outros pesquisadores também procuram acompanhar essas curvas, tal como Roberts (2014). As curvas estimadas por Michel Husson, revisadas e atualizadas, foram objeto de sua exposição no Third Economics Seminar of the IRRE, realizado em 2014, e são apresentadas nos Gráficos 2 e 3.

\section{Gráfico 2: Taxa de lucro e taxa de acumulação*}

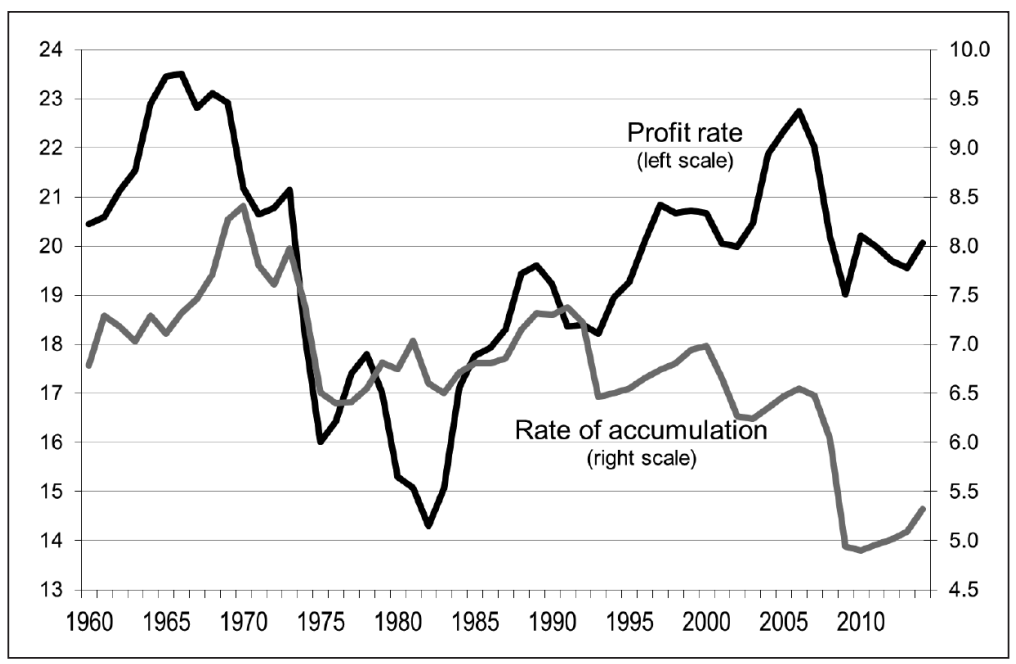

Fonte: Husson (2014). (*) EUA, Japão, Alemanha, França, Reino Unido e Itália, a partir dos dados da OCDE. 


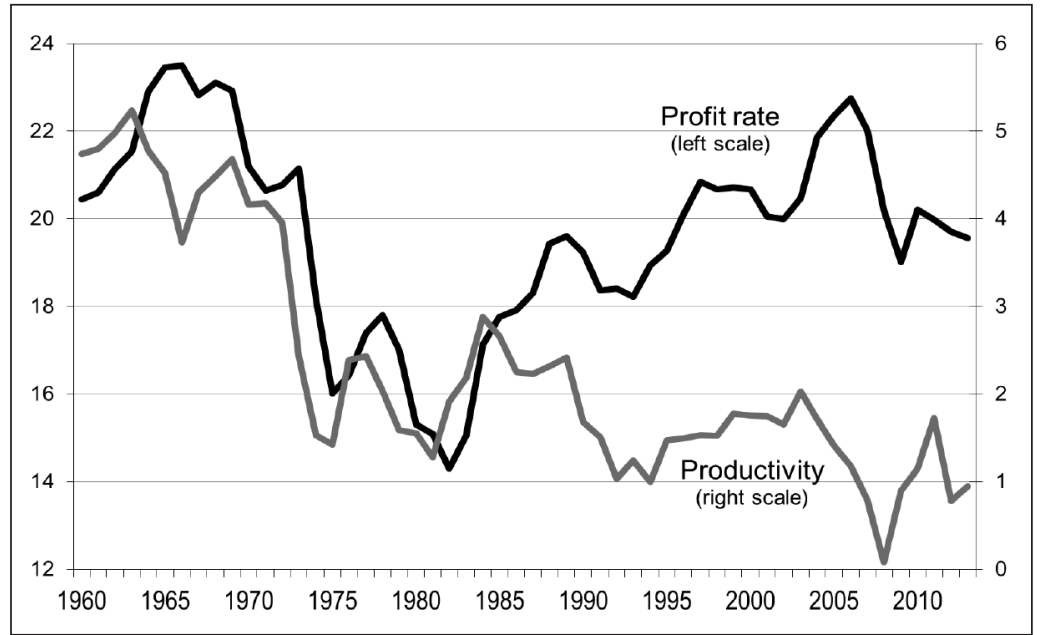

Fonte: Husson (2014). (*) EUA, Japão, Alemanha, França, Reino Unido e Itália, a partir dos dados da OCDE.

No Gráfico 2 fica evidente que, após 1975, as taxas de lucro e de acumulação não andam mais juntas, e que, a partir de 1992, quando a curva da taxa de lucros sobe a de acumulação cai, para quase todos os anos, com exceção da crise provocada pela suprime. Já no Gráfico 3 vê-se que a taxa de lucro não guarda mais relação com o aumento da produtividade desde 1984, e que esta última está significativamente abaixo da obtida em 1960, quando a economia mundial ainda crescia vigorosamente, criando empregos e renda.

A leitura desses gráficos permite dizer que, na raiz da crise dos anos 1970, encontra-se a queda da taxa de lucro, provocada pela redução do ritmo de crescimento da taxa de produtividade. Esta última, apesar da disseminação do uso de tecnologias com base na microeletrônica nas últimas décadas, não conseguiu recuperar seus níveis anteriores. Sua contínua queda, aliás, denota a impossibilidade dessa tecnologia apresentar resultados positivos, do ponto de vista macro, em uma situação de baixo crescimento. Isso porque, em geral, foi usada apenas para reduzir custos.

Pelo lado da taxa de lucro, mesmo se considerando a dificuldade atual de separar ganhos decorrentes da atividade industrial e comercial da financeira, o Gráfico 2 indica que houve recuperação da taxa de lucro a partir de 1984, sem que isso fosse acompanhado de expansão da taxa de investimento (acumulação). O resultado disso foi a aplicação crescente dos lucros no mercado financeiro.

Há autores que explicam a divergência entre a taxa de lucro e a da acumulação com base na rentabilidade mínima alcançada pelos ativos (de 15\%, segundo Plihon, 2005). Desse modo, a elevada rentabilidade propiciada pelo mercado de ativos atuaria como um obstáculo ao investimento, isto é, como decorrente da escolha entre investir e aplicar em ativos financeiros, dado que a taxa de lucro não se apre- 
sentaria tão atrativa. Esse tipo de interpretação introduz alguns problemas. Em primeiro lugar, tende a deslocar as razões da "disfuncionalidade" do capitalismo, patente quando se considera o tamanho do afastamento do volume de capital fictício com relação ao PIB mundial, para o próprio capital fictício, de modo que a causa torna-se consequência. A expansão do capital portador de juros, especialmente em sua forma fictícia, foi propiciada pela ampla desregulamentação promovida, os chamados três Ds: "a desregulamentação ou liberalização monetária e financeira, a descompartimentação dos mercados financeiros nacionais e a desintermediação, a saber, a abertura das operações de empréstimos, antes reservada aos bancos, a todo tipo de investidor institucional" (CHESNAIS, 2005, p. 46).

Essa desregulamentação foi capitaneada pelos Estados Unidos e pela Inglaterra como resposta ao esgotamento da base sobre a qual se assentou o período de trinta anos do pós-II Guerra Mundial (II GM), conhecido como trinta anos dourados. Sobre esse esgotamento e mesmo sobre a reação a isso, vários autores já escreveram (AGLIETTA, 1979; CHESNAIS, 2016)3. Aqui se trata tão somente de chamar a atenção para o fato de as condições que permitiram o crescimento desenfreado do capital fictício terem sido dadas pela desregulamentação e que não foi ele que impediu (impede) o crescimento do investimento. Na tentativa de recompor as condições da lucratividade, advogou-se a supremacia do mercado e a diminuição da presença do Estado na regulação da economia e da vida social. As políticas que concedem concretude a esses princípios deram corpo ao que se identifica como neoliberalismo. Mas para tentar recompor as condições de lucratividade não era possível falar-se somente em nome das empresas industriais, por exemplo. Era preciso alçar a "liberdade" de ação (com tudo que isso implica) ao lugar de uma necessidade para todos os capitais, ou melhor, como uma norma ideal de funcionamento de todas as atividades econômicas.

$\mathrm{O}$ aparente paradoxo estabelecido entre o comportamento da taxa de lucro e da taxa de acumulação, no lugar de expressar o resultado de uma "escolha de portfólio", denota que o capitalismo não conseguiu restabelecer as condições necessárias para uma retomada de um investimento contínuo. Entre essas condições, salienta-se o fato de a taxa de lucro não ter recuperado o nível atingido ao final dos anos 1960, mesmo que não se considere que parte da taxa de lucro de 1984 em diante pode estar "contaminada" por "lucros" financeiros. Além disso, há autores marxistas, entre eles Chesnais (2016) que chamam a atenção para o fato de as grandes

\footnotetext{
${ }^{3}$ Esses e outros pesquisadores chamam a atenção para o fato de que esses países só puderam capitanear o processo de desregulamentação dos mercados porque infringiram um duro golpe em seus trabalhadores (derrota da greve dos aeroviários, nos Estados Unidos, e da greve dos mineiros, na Inglaterra), de modo a alterar a correlação de forças anteriormente existente, quando os trabalhadores detinham a iniciativa na relação capital / trabalho. O reconhecimento desse fato e da importância dos três Ds no retorno do capital portador de juros ao centro das decisões econômicas e sua expansão desmesurada implica dizer que somente uma radical alteração do ambiente e das normas (em relação ao que vigorou nos trinta anos dourados) permitiu que o capital, sem entraves, aflorasse toda a sua vocação de fazer dinheiro sem passar pela produção.
} 
empresas trabalharem com elevada capacidade ociosa, de modo que esse indicador reflete sua situação de superprodução ou de superacumulação existente.

$\mathrm{E}$, ao isso não acontecer, a presença de um mercado financeiro que garante alta rentabilidade retroalimenta a evolução em direção contrária, entre a taxa de lucro e do investimento. Por sua vez, a diferença entre o comportamento da taxa de lucro e a da produtividade revela que a retomada do crescimento da primeira (apesar da ressalva anteriormente mencionada) deveu-se ao aumento significativo do grau de exploração da força de trabalho. É isso que indica a queda da participação dos salários na renda nacional nas principais economias do mundo, o aumento do nível de desigualdade e a manutenção de elevadas taxas de desemprego. Para isso, foi essencial o processo de mundialização do capital, que permitiu opor os trabalhadores no plano mundial. Uma das principais consequências da livre mobilização do capital é a redução de salários e a piora nas condições de trabalho, inclusive com relação à jornada de trabalho de parte significativa dos ocupados.

\section{Algumas implicações da dominância do capital fictício}

Além do provável papel inibidor do desenvolvimento do capital fictício sobre o capital produtivo, tratado acima, é necessário mencionar dois aspectos a ele relacionado e que têm forte impacto sobre as condições de reprodução dos trabalhadores. Trata-se, em primeiro lugar, do que é chamado de "fragilização das empresas" (PLIHON, op. cit.).

A desregulamentação e a mundialização do capital provocaram uma mudança qualitativa nas estruturas de controle e de propriedade do capital das empresas. Apesar de a internacionalização não ser um processo novo, com destaque para a expansão das multinacionais depois do fim da II GM, inclusive para os países da América Latina, especialmente para o Brasil, houve nas últimas décadas um aprofundamento da estrangeirização da propriedade. Além da privatização que decorreu do questionamento do papel do Estado, resultando na venda de empresas e na entrega para o mercado da exploração da prestação de serviços e ações até então sob sua responsabilidade, a liberdade concedida aos "investidores institucionais" pelos três Ds permitiu que empresas passassem a ser controladas não só por estrangeiros, mas por estrangeiros que têm como único objetivo obter altas taxas de rentabilidade e no curto prazo. Esses estrangeiros, que podem ser fundos de pensão, por exemplo, não têm nenhum compromisso de médio ou longo prazo com a empresa, de modo que não têm interesse em investir ou a preservar o nível de atividade ou o número de filiais.

Além disso, a liberdade de ir e vir que o capital financeiro adquiriu nas últimas décadas foi acompanhada por ganho de poder do acionista minoritário. Este, a qualquer sinal adverso ou ao vislumbrar melhor rentabilidade em outro lugar, retira-se de sua posição, o que é seguido por outros, e assim a empresa se desestabiliza. É devido ao fato de os acionistas minoritários visarem apenas rentabilidade de curto prazo, de verem as empresas apenas como um ativo financeiro, que Dominique Plihon (op. cit., p. 140) diz que eles, "definem que os objetivos perseguidos 
pelas empresas devem ser orientados prioritariamente em direção à 'criação de valor acionário', isto é, em direção à maximização do valor do patrimônio dos acionistas”.

O objetivo de valorização da ação, imposto pelos acionistas minoritários, tem como consequência o fato de as empresas adotarem como critério de gestão o EVA (Economic Value Added - Valor Econômico Agregado), que consiste em administrar a empresa em função da rentabilidade dos capitais em cada filial, fábrica ou componente. Esse tipo de gestão implica a reorganização da empresa a partir de centros de lucro, nos quais é aplicado o critério do valor acionário. Daí decorre que, mesmo quando uma linha de produção ou uma filial é lucrativa, são promovidos fechamentos de linha de produção com vistas a melhorar o resultado do centro de lucro. Vale lembrar que o EVA é fixado no mercado internacional; para seu cálculo, são aplicadas normas que variam conforme o setor de atividade. Diz Plihon (op. cit., p. 140):

$\mathrm{Na}$ forma atual do capitalismo, é demandado às empresas não só produzir lucros (o que era o objetivo dos capitais sob o regime fordista), mas igualmente obter uma rentabilidade dos capitais engajados igual ou superior às normas internacionais fixadas pelos investidores (bench marking). É assim que os grupos são conduzidos a deslocalizar ou a fechar unidades produtivas que obtém resultados positivos, mas cuja rentabilidade é julgada insuficiente na escala internacional.

Se à gestão imposta pelos acionistas minoritários somarmos o fato de parte da remuneração de gerentes-chave ser formada de stock options, vemos que a busca pela valorização acionária só poderia se firmar como norma da empresa e que a margem para aplicação de uma política de longo prazo é bastante reduzida. As stock options teriam constituído um dos fundamentos do compromisso estabelecido entre a classe capitalista e a fração superior dos assalariados, tal como defendem Duménil e Lévy (2010).

A incorporação da lógica imediatista do capital fictício no interior das empresas tem, é claro, grande reflexo sobre o nível de emprego e a renda dos ocupados. Isso porque, ao retroalimentar a tendência de níveis baixos de investimento produtivo, ao provocar fechamento de filiais e/ou departamentos e ao incentivar a deslocalização das empresas, não só mantém elevado o nível de desemprego como pressiona os salários a serem reduzidos. Não é por outro motivo que o desemprego, esquecido durante os trinta anos dourados, voltou a ser parte da vida "normal" do trabalhador e que os salários tenham significativamente perdido participação na renda nacional dos países.

\section{CONSIDERAÇÕES FINAIS}

A leitura dos capítulos do Livro III, volume V de O Capital, no qual Marx trata do capital portador de juros, nos permite entender que seu desenvolvimento 
atual, principalmente na forma de capital fictício, expressa a impossibilidade de o capital promover as condições necessárias para a reprodução da vida da maioria da população. Esse capital, enquanto "autômato perfeito" - dado que é "dinheiro que faz dinheiro sem passar pelas agruras da produção" -, ao não encontrar obstáculos para seu desenvolvimento, sejam eles de natureza política ou institucional, tende a se expandir autonomamente sem manter relação com a produção de novo valor. Expressão dessa possibilidade concreta é o fato de hoje o valor do capital fictício existente no mundo representar dez vezes o do PIB mundial.

Mas, como visto, não se trata de um cancro que, com sua expansão, põe em risco o conjunto dos outros capitais. O que Marx nos permite inferir é que essa é a forma acabada assumida pelo capital e que essa é a forma que todos os capitalistas desejariam possuir, dado que eles não reconhecem o trabalho como fonte da criação do novo valor. Lembremos que o capitalista industrial, ao considerar que o lucro é o simples resultado da diferença entre o preço (a que vende seu produto) e o custo envolvido na produção, não só deixa de reconhecer que a fonte do lucro é o trabalho assalariado, não distinguindo entre máquinas e homens, como desloca em parte o locus da produção do lucro da produção para a circulação. Já o capitalista comercial está "convencido" de que seu lucro se deve ao fato de ele comprar barato e vender caro. Daí, obter lucro em operações realizadas apenas na circulação, sem que haja algum vínculo com a produção de bens e serviços e, portanto, com a geração de mais valor, torna-se o ideal buscado por todo capitalista. Dito de outra maneira, no lugar de um cancro, o capital fictício é o capital na sua plenitude, quando a ele não se contrapõe barreiras.

Como visto, para a expansão exacerbada desse capital, observada nas últimas décadas, foi necessário promover o desmonte dos sistemas de regulação construídos no pós-II GM, que restringiam sua liberdade de ação intra e entre os países. A desregulamentação ocorreu num quadro de esgotamento relativo das bases que sustentavam o ciclo expansivo de acumulação do período anterior (os trinta anos dourados), que se manifestou na queda da taxa de lucro nos principais países capitalistas. Assim, a defesa da desregulamentação não se restringiu às atividades diretamente relacionadas ao capital portador de juros e foi (é) advogada como condição necessária para o desenvolvimento de todos os capitais. Em outras palavras, o mercado foi alçado ao locus ideal dos arranjos perfeitos, no qual o Estado deve ser afastar ao máximo.

Nesse processo, a lógica imediatista do capital fictício se opõe à perspectiva de longo prazo própria do investimento do capital função (industrial ou comercial). Daí se observar que vivemos um período de baixo crescimento e investimento, no qual parte dos lucros não distribuídos é dirigida à compra de ativos financeiros de todo tipo. Mas, do ponto de vista concreto, não podemos sustentar a existência de conflito entre o capital portador de juros e o capital função, pois o grande capital industrial e comercial atua simultaneamente no chamado mercado de ativos, devendo parte importante de sua rentabilidade às aplicações nessa esfera. 


\section{REFERÊNCIAS BIBLIOGRÁFICAS}

AGLIETTA, Michel (1979) Regulación y crisis del capitalismo. México, Siglo Ventiuno Editores.

AGLIETTA, Michel (2003) "Le risque système dans la finance libéralisée" . In Revue d’Économie Financière, $\mathrm{n}^{\circ}$ 70, p 35 - 50, 2003. Paris, 2003.

ANDRADE, Patrick Rodrigues; MARQUES, Rosa Maria (2017) "O capital como "antivalor": considerações sobre a mercadoria-capital e o fetiche-perfeito". Revista da Sociedade Brasileira de Economia Política, n. 46.

CARCANHOLO, Reinaldo e NAKATANI, Paulo (2007) "Capitalismo especulativo y alternativas para América Latina”. Buenos Aires, Herramienta, $\mathrm{n}^{\circ} 35$, junio.

CHESNAIS, François. (2005) "O capital portador de juros: acumulação, internacionalização, efeitos econômicos e políticos”. In A finança mundializada. Org. F. Chesnais. São Paulo, Boitempo.

CHESNAIS, François (2007) "Sur la portée et le cheminement de la crise financière". Paris, Carré Rouge, p. 17 a 31.

CHESNAIS, François (2016) Finance capital today - corporations and Banks in the lasting global slump. Boston: Brill, 2016.

DUMÉNIL, Gérard e LÉVY, Dominique (2010) “A finança capitalista: relações de produção e relações de classe”. In A finança capitalista, São Paulo: Alameda.

HUSSON, Michel. (2010) "Finança, hiper-concorrência e reprodução do capital”. In A finança capitalista. São Paulo: Alameda.

HUSSON, Michel (2014) Apresentação de Michel Husson no Third Economics seminar of the IRRE. Amsterdã, 2014. Vídeo disponível em: https://www.iire.org/node/640.

ORLEAN, André. (1999) Le pouvoir de la finance. Paris : Odile Jacob.

LORDON, Frédéric (2003) Fonds de pension, pièges à cons? Paris: Raisons d'Agir, 2003.

MARQUES, Rosa Maria (2015) “O lugar das políticas sociais no capitalismo contemporâneo”. Argumentum, Vitória (ES), v. 7, n. 2, p. 7-21.

MARQUES, Rosa Maria; NAKATANI, Paulo. “A natureza do capitalismo contemporâneo”. In José Eduardo Cassiolato; Marcelo Pessoa de Matos; Helena M. M. Latres, orgs, Desenvolvimento e Mundialização: o Brasil e o pensamento de François Chesnais. Rio de Janeiro: E-Papers.

MARX, Karl. (1996) O capital: crítica da economia política. Volume I, tomo 1. São Paulo: Nova Cultural.

MARX, Karl (1986a) O capital: crítica da economia política. Volume III, tomo 1. São Paulo: Nova Cultural.

MARX, Karl (1986b) O capital: crítica da economia política. Volume III, tomo 2. São Paulo: Nova Cultural.

PLIHON, D. (2005) “As grandes empresas fragilizadas pela finança”. In CHESNAIS, F. (org.) A finança mundializada, raízes sociais e políticas, configuração, conseqüências. São Paulo: Boitempo.

ROBERTS, Michel (2014) "Tendencies, triggers and tulips - The causes of the crisis: the rate of profit, overaccumulation and indebtedness". Apresentação de Michel Roberts no Third Economics seminar of the IRRE. Amsterdã, 2014. Disponível em https://fileserver.iire.org/working_papers/ WP37-Roberts.pdf. 